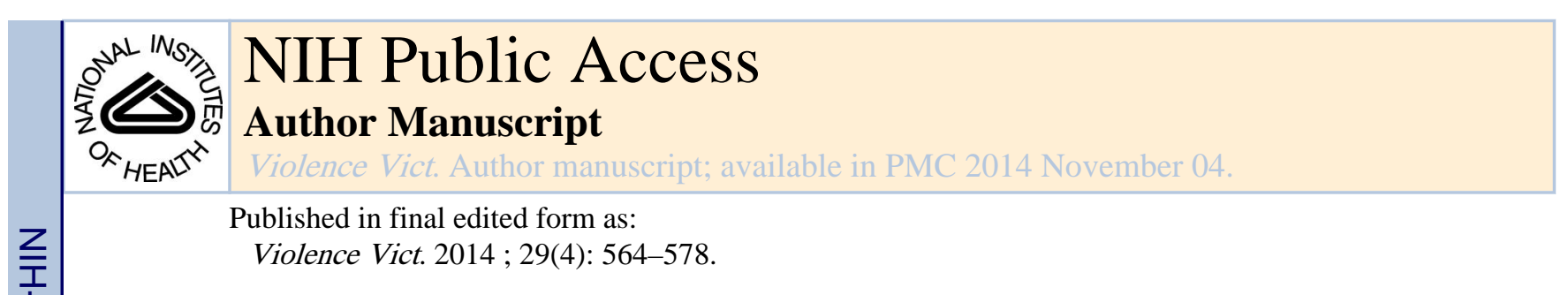

\title{
Anger-Related Dysregulation as a Factor Linking Childhood Physical Abuse and Interparental Violence to Intimate Partner Violence Experiences
}

\author{
Katherine M. Iverson, PhD, \\ National Center for PTSD, VA Boston Healthcare System, Boston University School of Medicine
}

Katie A. McLaughlin, PhD,

Department of Psychology, University of Washington

Kathryn C. Adair, MA, and

University of North Carolina at Chapel Hill

Candice M. Monson, PhD

Ryerson University, Toronto, Canada

\begin{abstract}
Objective-Childhood family violence exposure is associated with increased risk for experiencing intimate partner violence (IPV) in adulthood, but the mechanisms underlying this relationship remain inadequately understood. Difficulties with emotion regulation may be one factor that helps to explain this relationship.
\end{abstract}

Method-Childhood physical abuse and interparental violence, as well as subsequent IPV experiences, were assessed in a large sample of young adults $(N=670)$. Several indicators of anger-related dysregulation were also assessed. Structural equation modeling was used to create a latent variable of anger-related dysregulation, which was examined as a potential mediator of the associations between childhood family violence exposure and IPV.

\begin{abstract}
Results-Childhood physical abuse and interparental violence were associated with greater physical, sexual, and emotional IPV victimization. Childhood physical abuse and interparental violence were also associated with anger-related dysregulation, which was positively associated with all three types of IPV experiences. Anger-related dysregulation fully mediated the association between witnessing interparental violence and physical IPV. Anger-related dysregulation partially mediated the association between witnessing interparental violence and psychological IPV and the associations of childhood physical abuse with all three forms of IPV. These associations were consistent across gender.
\end{abstract}

Conclusions-Interventions aimed at reducing IPV risk among survivors of childhood family violence may benefit from including techniques to target anger-related emotion regulation skills.

(C) 2014 Springer Publishing Company

Correspondence regarding this article should be directed to Katherine M. Iverson, PhD, WHSD (116B-3) VA Boston Healthcare System, 150 South Huntington Ave., Boston, MA 02130. Katherine.Iverson@ va.gov.

The content is solely the responsibility of the authors and does not represent the official views of the Department of Veterans Affairs. 


\section{Keywords}

domestic violence; childhood maltreatment; emotion dysregulation; anger; gender

Intimate partner violence (IPV) is a significant public health problem impacting women and men in the United States (Black et al., 2011). IPV is most common among young adults, with the highest prevalence rates documented among individuals in their late teens and early- to mid-20s (O'Leary, 1999). In this age group, physical and/or sexual IPV victimization occurs in approximately 20\%-37\% of dating relationships (Shorey, Cornelius, $\&$ Bell, 2008). Psychological abuse is also common among young adults (Shorey et al., 2008). The mental health consequences of each of these three forms of IPV experiences include shame; guilt; and elevated risk for post-traumatic stress disorder (PTSD), other anxiety disorders, depression, substance misuse, somatic complaints, and suicidality (Campbell, 2002; Iverson et al., 2012; Street \& Arias, 2001).

Several studies suggest that childhood family violence exposure is associated with increased risk for experiencing IPV in adulthood (Coid et al., 2001; Desai, Arias, Thompson, \& Basile, 2002; Whitfield, Anda, Dube, \& Felitti, 2003). In particular, a growing literature demonstrates that childhood physical abuse and witnessing interparental violence are associated with subsequent IPV victimization in both cross-sectional and longitudinal studies (Bensley, Eenwyk, \& Wynkoop Simmons, 2003; Ehrensaft et al., 2003; Iverson, Jimenez, Harrington, \& Resick, 2011; McKinney, Caetano, Ramisetty-Mikler, \& Nelson, 2009). For example, a 20-year prospective study found that witnessing interparental violence was associated with a threefold increase in risk for IPV victimization in adulthood (Ehrensaft et al., 2003). However, previous work suffers from several methodological limitations, including substantial variations in definitions and measurements employed across studies and scant attention to mediators of associations between childhood family violence exposure and IPV experiences (Riggs, Caulfield, \& Fair, 2009). In particular, there has been limited empirical attention to individual characteristics of individuals who experience IPV because of concerns related to "victim blaming." Although such concerns are legitimate, it is critical to identify factors that can be identified by clinicians and survivors of childhood family violence to help reduce their risk for IPV (Cattaneo \& Goodman, 2005).

Although childhood family violence exposure appears to be a risk factor for experiencing IPV in adulthood, the mechanisms underlying this association are poorly characterized. Impaired psychosocial functioning, as indexed by the presence of mental health symptoms, has been proposed as a potential pathway through which childhood family violence exposure increases vulnerability to IPV experiences (see Classen, Palesh, Aggarwal, 2005). However, a recent longitudinal study of young adults demonstrated that neither symptoms of depression and anxiety nor substance abuse mediated the relationship between childhood physical abuse and IPV victimization (Lindhorst, Beadnell, Jackson, Fieland, \& Lee, 2009). Milner et al. (2010) found that trauma symptomatology was a mechanism linking childhood physical abuse to violence perpetration among adults; however, this study did not examine 
whether trauma symptoms mediated the relationship between childhood physical abuse and IPV victimization.

Theoretical writings posit that emotion regulation problems stemming from childhood family violence exposure may underlie the psychosocial problems documented among adult interpersonal trauma survivors (e.g., Cloitre, Cohen, \& Koenen, 2006; Ford, Courtois, Steele, van der Hart, \& Nijenhuis, 2005). Emotion dysregulation refers to a broad array of difficulties in understanding, responding to, expressing, and managing emotional responses (Mennin, Holaway, Fresco, Moore, \& Heimberg, 2007). Emotion regulation abilities develop in early childhood, with the family environment substantially impacting the success of emotion regulation development (Cummings \& Davies, 1994; Linehan, 1993).

There is reason to believe that emotion dysregulation may be an important factor linking childhood family violence exposure to risk for IPV experiences. First, it is well documented that early stressful life events, including childhood physical abuse and exposure to interparental violence, leads to an array of emotion regulation deficits (e.g., emotional awareness, poor management of frustration and anger) and contributes to emotion dysregulation among children (Camras et al., 1988; McLaughlin \& Hatzenbuehler, 2009; Repetti, Taylor, \& Seeman, 2002). It is possible that emotion dysregulation displayed by parents through aggressive acts toward a child and/or partner negatively affects the ability of children to learn to effectively regulate their emotions (Cummings \& Davies, 1994).

In addition to theoretical and empirical support for the link between childhood family violence exposure and emotion dysregulation, a burgeoning literature demonstrates an association between emotion dysregulation and interpersonal victimization in adulthood, although most work has focused on sexual revictimization among women as opposed to IPV per se (see Marx, Heidt, \& Gold, 2005). For example, Cloitre, Scarvalone, and Difede (1997) found that women who experienced sexual abuse in childhood and adulthood had greater difficulty labeling and expressing their emotions relative to women who experienced no such revictimization. Early abuse experiences were postulated to contribute to the development of emotion regulation difficulties, which in turn, contributed to victimization risk through interference with risk detection abilities (Cloitre et al., 1997). In a more recent study, Berzenski and Yates (2010) found that childhood emotional abuse was positively associated with emotion dysregulation as well as IPV perpetration and victimization. Similar relations were evident with respect to childhood physical, sexual, and emotional abuse and witnessing interparental violence. Moreover, emotion dysregulation emerged as a significant mediator of the observed relation between childhood emotional abuse and IPV (Berzenski \& Yates, 2010). Although preliminary, these studies provide initial support for the notion that emotion dysregulation may help explain the association between childhood family violence exposure and IPV experiences in adulthood.

To inform prevention efforts, it is important to identify specific emotion dysregulation processes that increase IPV victimization risk among survivors of childhood family violence. One form of emotion dysregulation associated with both a history of childhood family violence exposure and IPV victimization is anger-related dysregulation (Sappington, Pharr, Tunstall, \& Rickert, 1997). Drawing on social learning theory (Bandura, 1973), 
anger-related dysregulation, or an inability to manage and express anger effectively, may be learned through the observation and imitation of others' behaviors and through direct behavioral conditioning from parental figures. Anger dysregulation (e.g., experiencing high levels of anger arousal in the absence of effective methods for regulating the arousal to meet one's goals) may increase risk for victimization through interfering with information processing and risk detection (Marx et al., 2005). For example, individuals who have experienced childhood family violence and have difficulties regulating angry affect may experience high-intensity anger responses in various situations, making it difficult to identify potential partners and situations that truly portend danger. Someone who experiences anger dysregulation may be so overwhelmed or focused on these internal cues that they have trouble detecting cues in their environment that signal risk (Marx et al., 2005).

Consistent with this theory, empirical work has demonstrated that childhood physical abuse and interparental violence exposure are associated with anger-related dysregulation in children and adults (Cicchetti \& Toth, 2005; Repetti et al., 2002; Sappington et al., 1997). For example, exposure to family violence has been shown to increase sensitivity to anger in children (Repetti et al., 2002). Similarly, preliminary data suggest a link between angerrelated dysregulation and IPV victimization. Rutter, Weatherill, Taft, and Orazem (2012) found that various indicators of anger, including suppression and expression, were associated with IPV victimization among young adults. Although significant associations were found between anger and IPV victimization for men and women, the strength of associations were generally stronger for men than women (Rutter et al., 2012).

Although anger-related dysregulation is a potentially important psychological sequelae of childhood violence exposure and potential determinant of IPV experiences, the role of anger-related dysregulation as a factor linking childhood family violence exposure and IPV victimization has rarely been examined. The purpose of this investigation was to address this gap in the literature using cross-sectional data from a large sample of young adults that included assessments of childhood exposure to physical abuse and interparental violence, experiences of IPV in current or former relationships, and anger-related dysregulation. We hypothesized that both childhood physical abuse and witnessing interparental violence would be positively associated with anger-related dysregulation and with IPV victimization. Furthermore, we hypothesized that anger-related dysregulation would mediate the association between childhood family violence exposure and IPV victimization. A secondary aim of this study was to explore these associations in men and women because there may be gender differences in psychosocial functioning and IPV risk following family violence exposure (Afifi et al., 2008; Desai et al., 2002; Iverson et al., 2011). Similarly, prior work suggests that the strength of the associations between anger-related dysregulation and IPV may differ by gender (Rutter et al., 2012).

\section{METHOD}

\section{Participants}

Participants were 670 young adults (442 women, 228 men) at a large midwestern university who were participating in a larger survey study of dating violence (Monson \& 
Langhinrichsen-Rohling, 2002). An initial sample of 2,000 students (1,000 men, 1,000 women) was randomly selected from a list of registered undergraduates to receive the survey; thus, the response rate was $34 \%$. The mean age of the sample was $21.22(S D=3.60)$ years. The sample was predominantly White (93.8\%) and included 1.2\% Hispanic, $1 \%$ African American, 1.2\% Asian American, and 2.8\% who described themselves as "other" racial/ethnic backgrounds. Additional information on the parent study can be found in Monson and Langhinrichsen-Rohling (2002).

\section{Measures}

Childhood Family Violence Exposure and IPV—The revised Conflict Tactics Scales (CTS-2; Straus, Hamby, McCoy, \& Sugarman, 1996) was used to assess participants' exposure to childhood physical abuse, interparental violence, and early adult IPV victimization. The CTS-2 measures psychologically aggressive (e.g., insults or swearing), physically abusive (e.g., push, grab, or slap), and sexually coercive (e.g., used threats to have oral or anal sex) behaviors in interpersonal relationships. The internal consistency and reliability of the CTS-2 scales is good, and support for the CTS-2's construct and discriminant validity has been established (Straus et al., 1996).

The CTS-2 was modified in this study to simplify and shorten the assessment of constructs of interest. First, only the severe physical abuse items for the CTS-2 were combined into one dichotomous question ("yes" or "no" response option) to assess for the presence of exposure to childhood physical abuse and interparental violence. Specifically, childhood physical abuse was assessed by the following question: "Has/have parent(s) or stepparent(s) done any of the following things to you: used a knife or gun against you, punched you, hit you with something that could hurt you, choked you, slammed you against the wall, beat you up, burned or scalded you, or kicked you?" Although using the CTS-2 to assess childhood physical abuse has limitations (Straus \&Hamby, 1997), the modification has had success in measuring childhood physical abuse and has been used in many other research studies (Straus, 1995). Witnessing interparental violence was assessed by the following question: "Have you ever seen or heard your parents or stepparents do any of the following things: use a knife or gun against the other, punch or hit the other with something that could hurt, choke the other, slam the other against a wall, beat the other up, burn or scald the other, or kick the other?"

In addition, only physical and psychological IPV victimization were assessed using the CTS-2. Sexual IPV victimization was assessed with another measure described later. Lifetime exposures to physical and psychological IPV victimization were assessed by summing the number of positively endorsed items for each scale, with total scales ranging from 0 to 12 for physical IPV and $0-8$ for psychological IPV. This computation method, referred to as the variety score, has desirable psychometric properties, reduces estimation errors common in the recall of high-frequency behaviors, and circumvents the need to weight different acts by their presumed severity (Moffitt et al., 1997). These changes to the CTS-2 are consistent with modifications of this measure used in previous research on childhood family violence and IPV (McKinney et al., 2009; Milner et al., 2010; Whitfield et 
al., 2003). The internal consistency of the subscales of the CTS-2 was good in this study $(K R 20=.79$ and .78 , for physical and psychological IPV, respectively).

The Sexual Assault Measure (SAM; Monson \& Langhinrichsen-Rohling, 1997) was used to assess sexual IPV victimization. The SAM is a compilation of the items from the Sexual Experiences Scale (Koss \& Oros, 1982) and the sexual coercion subscale of the CTS-2 (Straus et al., 1996). Sexual IPV was measured with the SAM because the CTS-2 provides a relatively limited number of sexual IPV experiences and has been shown to have less than ideal psychometric properties (Vega \& O'Leary, 2007). The SAM includes nine sexual behaviors, performed without the respondent's consent by a past or current intimate relationship partner (defined as current or former girlfriend or boyfriend). The behaviors identified on the SAM assess the presence or absence of three levels of various forms of unwanted sexual activity (i.e., sex play, vaginal sexual intercourse, oral/anal intercourse). Similar to the assessment of psychological and physical IPV using the CTS-2, sexual aggression on the SAM was assessed by summing the number of different abusive acts endorsed. The internal consistency of the SAM in this sample was good $(K R 20=.78)$.

Anger-Related Emotion Dysregulation-The Multidimensional Anger Inventory (MAI; Siegel, 1986) is a 38-item self-report scale that assesses several dimensions of anger: frequency, duration, magnitude, mode of expression, hostile outlook, and range of angereliciting situations. The MAI includes three primary subscales: anger arousal, anger-eliciting situations, and hostile outlook. We drew our items from the anger arousal scale of the MAI, which includes items reflecting both under- and overregulation of anger. Example items used in this study include the following: "Other people seem to get angrier than I do in similar situations," "When I hide my anger from others, I forget it pretty quickly," "It's difficult for me to let people know I'm angry," "It is easy to make me angry," and "I am surprised at how often I feel angry." Respondents rate the degree to which the items are characteristic of them on a 5-point scale ranging from completely uncharacteristic to completely characteristic. Higher scores reflect higher levels of anger-related dysregulation. Siegel (1986) reports adequate test-retest reliability and high internal consistency for the MAI. The MAI demonstrated good internal consistency in this study $(a=.85)$.

Respondents also completed the Structured Clinical Interview for DSM-III-R-Personality Disorders (SCID-II), Screening Questionnaire-Modified (Spitzer, Williams, Gibbon, \& First, 1990). Given that borderline personality disorder can be conceptualized as a problem of chronic emotion dysregulation (Linehan, 1993), two items from the Borderline Personality Disorder subscale were used, including one indicator of mood dysregulation ("I am a moody person") and one indicator of anger arousal ("Even little things get me very angry"). In its original form, the screening questionnaire asks the respondent to indicate whether or not each characteristic is indicative of the person they "generally are, that is, how you usually have felt or behaved over the past several years." Responses are provided on a 5-point scale ranging from "completely undescriptive of me" to "completely descriptive of me." The two borderline personality items demonstrated adequate internal consistency in this sample $(a=.65)$. 


\section{Procedure}

Participants were mailed a packet of study materials consisting of a cover letter inviting them to participate, self-report questionnaires, and a stamped self-addressed envelope. The cover letter indicated that participants who mailed back their self-report packets were providing their consent to participate in the study. Four participants were randomly selected to receive $\$ 75$ cash at the conclusion of data collection. All of the procedures described in this study were approved by a university institutional review board.

\section{Data Analytic Plan}

Structural equation modeling was used to perform the mediation analyses using AMOS 6.0 software (Arbuckle, 2005). Analyses were conducted using the full information maximum likelihood estimation method, which estimates means and intercepts to handle missing data. As described in the following text, a latent variable representing anger-related dysregulation was created using 11 observed variables of anger and mood dysregulation. After testing the fit of the measurement model, the mediation analyses first examined the association between childhood family violence exposures and subsequent IPV victimization. Childhood physical abuse and exposure to interparental violence were examined separately. Second, associations between childhood family violence exposures and anger-related dysregulation were examined. Third, we examined the associations between anger-related dysregulation and physical, sexual, and psychological forms of IPV victimization. The full mediation model was examined using the product of coefficients method to evaluate the hypothesis that anger-related dysregulation mediates the association between childhood family violence exposures and IPV victimization in adulthood. Sobel's (1982) standard error approximation was used to test the significance of the intervening variable effect. The product of coefficients approach is associated with low bias and type 1 error rate, accurate standard errors, and adequate power to detect small effects (MacKinnon, Lockwood, Hoffman, West, $\&$ Sheets, 2002). The mediation model was examined for physical, sexual, and psychological forms of IPV separately to determine whether mediation effects were consistent across subtypes of IPV experiences.

Finally, we examined participant sex as a moderating variable. Multigroup analyses were conducted to examine whether the process of mediation was moderated by sex. Each of the mediation paths was constrained to be equal for men and women, and the difference in model fit was examined using a chi-square test.

\section{RESULTS}

\section{Descriptive Statistics}

Table 1 displays the prevalence of exposure to childhood physical abuse; to interparental violence; and to physical, sexual, and psychological forms of IPV by sex. The proportions of exposure to victimization in this sample is similar to what has been observed in other samples of young adults (e.g., McKinney et al., 2009). Women were more likely to report sexual IPV relative to men, $F(1,669)=31.62, p<.001$. No other sex differences were observed. Table 2 provides the bivariate correlations among IPV victimization and childhood family violence variables. As expected, childhood physical abuse and witnessing 
interparental violence was positively associated with early adult IPV victimization and anger-related dysregulation, which were positively associated with one another. The only exception was that witnessing interparental violence was not associated with sexual IPV victimization.

\section{Measurement Model}

The measurement model of anger-related dysregulation was constructed using 11 indicator variables: 9 indicators of dysregulated expression of anger and anger arousal drawn from the MAI and 2 indicators of mood dysregulation from the Personality Disorders Screening Questionnaire. The specific items were selected using exploratory factor analysis (Costello \& Osborn, 2005). Specifically, we conducted an exploratory factor analysis to determine whether the anger arousal items from the MAI loaded onto a single factor in our data in a similar fashion as has been reported in other studies (e.g., Siegel, 1986). Some items on the anger arousal scale did not load with the other items in our sample (e.g., "Other people seem angrier than I do in similar circumstances"). These items were dropped. We completed the confirmatory factor analysis on the 9 items from the anger arousal scale that loaded onto a single factor in our sample along with 2 items from the SCID-II that tapped a similar dimension of anger-related dysregulation. The measurement model that provided the best fit to the data was selected using standard model fit indices. Values of the comparative fit index (CFI) exceeding .95 indicate adequate fit, and the root mean square error of approximation (RMSEA) should be less than .06 (Hu \& Bentler, 1999). For the hypothesized model, CFI $=.95$ and RMSEA $=.06$ (90\% CI [.05-.07]). Thus, fit indices indicated that the measurement model of anger-related dysregulation fit the data well. However, the chi-square test of independence revealed a significant difference between the observed and reproduced covariance matrices $\chi^{2}(54)=190.75, p<.001$. In large samples, even small differences between the observed and reproduced matrices can lead to a significant chi-square test. The large sample size of this study may be driving the significant chi-square value.

\section{Mediation Analyses}

Childhood Physical Abuse-Anger-related dysregulation was first examined as a mediator of the association between childhood physical abuse and early adult IPV victimization. Childhood physical abuse was significantly associated with physical, $\beta=.14$, $p<.001$; sexual, $\beta=.11, p<.005$; and psychological IPV victimization, $\beta=.15, p<.001$. Childhood physical abuse also was associated with anger-related dysregulation, $\beta=.18, p<$. 001. Anger-related dysregulation, in turn, was associated with physical, $\beta=.17, p<.001$; sexual, $\beta=.13, p<.005$; and psychological IPV victimization, $\beta=.17, p<.001$.

In the full mediation model, the association between childhood physical abuse and physical, $\beta=.12, p=.003$; sexual, $\beta=.09, p=.019$; and psychological IPV victimization, $\beta=.12, p$ $=.002$ were attenuated when anger-related dysregulation was added to the model but remained significant. Sobel's (1982) z-test revealed a statistically significant indirect effect of childhood physical abuse on early adult physical, $z=2.46, p=.014$; sexual, $z=2.36, p$ $=.018$; and psychological IPV victimization, $z=2.52, p=.012$ through anger-related dysregulation, suggesting that anger-related dysregulation represents a partial mediator of these associations. 
Witnessing Interparental Violence-We also examined the role of anger-related dysregulation as a mediator of the association between witnessing interparental violence and early adult IPV victimization. Witnessing interparental violence was associated significantly with physical, $\beta=.08, p<.05$ and psychological IPV, $\beta=.14, p<.001$ but not with sexual IPV victimization, $\beta=.01, p=.893$. Witnessing interparental violence was also associated with anger-related dysregulation, $\beta=.13, p<.001$, which was associated with physical, sexual, and psychological IPV victimization, as reported earlier.

In the full mediation model, the association between witnessing interparental violence and physical IPV victimization was no longer significant when anger-related dysregulation was added to the model, $\beta=.06, p=.123$ (see Figure 1). Sobel's (1982) z-test revealed a statistically significant indirect effect of witnessing interparental violence on physical IPV victimization through anger-related dysregulation, $z=2.52, p=.012$, indicating that angerrelated dysregulation was a full mediator of this association. In contrast, the association between witnessing interparental violence and psychological IPV victimization was attenuated when anger-related dysregulation was added to the model but remained significant, $\beta=.11, p=.004$. Sobel's z-test revealed a statistically significant indirect effect of witnessing interparental violence on psychological IPV victimization through angerrelated dysregulation, $z=2.48, p=.013$, suggesting that anger-related dysregulation was a partial mediator of these associations.

\section{Moderation Analyses}

We examined whether the role of anger-related dysregulation as a mediator of the associations between childhood exposures and early adult IPV victimization was modified by sex. We did not evaluate this possibility for witnessing interparental violence and sexual IPV because anger-related dysregulation did not mediate this association. When the mediation paths of interest were constrained to equivalence across men and women, the model fit for witnessing interparental violence did not significantly worsen for physical, $\chi^{2}(3)=6.5, p=.091$, or psychological IPV victimization, $\chi^{2}(3)=4.5, p=.216$. The model fit for childhood physical abuse did not worsen significantly for physical, $\chi^{2}(3)=7.7, p=$. 052; psychological, $\chi^{2}(3)=4.7, p=.198$; or sexual IPV victimization, $\chi^{2}(3)=6.3, p=.099$, indicating that the process and strength of mediation was consistent for participant sex.

\section{DISCUSSION}

Associations between childhood family violence exposure and IPV experiences in adulthood have been observed in previous studies (Bensley et al., 2003; Coid et al., 2001; Desai et al., 2002; Whitfield et al., 2003), yet it is not well understood how and why childhood family violence exposure might increase risk for experiencing IPV. Our results indicate that angerrelated dysregulation is a factor that helps to explain, in part, why individuals exposed to childhood family violence are more likely to experience IPV in early adulthood. We found statistical evidence that anger-related dysregulation fully mediated the association between witnessing interparental violence and physical IPV victimization and partially mediated the association between witnessing interparental violence and psychological IPV victimization for both men and women. Furthermore, we found statistical evidence that anger-related 
dysregulation partially mediated the associations between childhood physical abuse and physical, sexual, and psychological IPV victimization.

The current findings extend previous work by demonstrating that childhood violence exposure is associated with deficits in anger-related dysregulation that, in turn, are associated with increased risk for IPV victimization in young adulthood. The significant associations between anger-related dysregulation and both childhood physical abuse and exposure to interparental violence are consistent with theoretical work arguing that childhood family environments characterized by violence hinder the development of effective emotion regulation skills, particularly in the expression and modulation of anger (Cicchetti \& Toth, 2005; Cummings \& Davies, 1994; Linehan, 1993). Specifically, our findings are consistent with the notion that anger-related dysregulation may develop in childhood and persist into early adulthood, which may increase risk for experiencing IPV.

Anger-related dysregulation might increase vulnerability to IPV in several ways. For example, high levels of anger arousal paired with an inability to effectively modulate such arousal may interfere with one's ability to accurately identify and respond effectively to dangerous situations or people (Marx et al., 2005). Specifically, individuals who have difficulty expressing anger in a modulated way may experience high-intensity anger responses in various situations, making it difficult to identify those situations that are truly dangerous. Alternatively, individuals may partner with others with similar emotion regulation tendencies (Segrin, 2004), increasing the likelihood of becoming involved in relationships with partners who also experience high levels of anger-related dysregulation, elevating risk for IPV victimization. Importantly, previous research suggests that angerrelated dysregulation strongly relates to a wider range of emotion regulation problems, including poor emotional awareness and engagement in maladaptive cognitive emotion regulation strategies, such as suppression and rumination (McLaughlin, Hatzenbuehler, \& Hilt, 2009; McLaughlin, Hatzenbuehler, \& Phil, 2009; McLaughlin, Hatzenbuehler, Mennin, \& Nolen-Hoeksema, 2011). As a result, there are various emotion regulation deficits-in addition to anger-related dysregulation - that likely contribute to heightened risk of IPV victimization among those with exposure to child maltreatment. Examination of these additional emotion regulation pathways using prospective longitudinal studies represents an important goal for future research to more fully determine if childhood family violence exposure leads to problems with anger dysregulation which then account partially or fully for the risk of adult IPV experiences.

It is important to acknowledge existing evidence suggesting that the relationship between childhood maltreatment and IPV perpetration among male young adults is mediated by emotion dysregulation (Gratz, Autumn, Jakupcak, \& Tull, 2009). Emotion regulation deficits also have been observed among couples who engage in bidirectional IPV (i.e., both partners experience IPV in the relationship; McNulty \& Hellmuth, 2008). Such research suggests that emotion regulation difficulties stemming from childhood violence exposure may also increase risk of IPV perpetration, which in turn increases risk for IPV victimization through bidirectional IPV. Clearly, additional research is needed to elucidate the manner by which specific emotion dysregulation processes-including, but not limited to, anger-related dysregulation-contribute to IPV risk. Although anger-related dysregulation may contribute 
to IPV risk, it should not be used to blame individuals for the aggression they experience. The responsibility for IPV belongs to the individual who uses the aggression.

It is important to note that anger-related dysregulation was as a partial mediator of most of the associations observed between childhood family violence exposure and IPV victimization. Thus, it is likely that additional factors, such as psychopathology, social skills deficits, dissociation, or attachment styles may also underlie the observed association between child family violence exposure and IPV victimization. Children who experience childhood family violence are more likely to develop mental health problems, such as PTSD, which may interact with emotion regulation difficulties or contribute independently to increased risk for IPV (Messman-Moore \& Long, 2003). Although our findings indicate that anger-related dysregulation is an important factor linking child abuse or witnessing interparental violence and adult IPV victimization, additional pathways linking violence exposure to subsequent victimization warrant further investigation. This study focused on a specific form of emotion dysregulation, specifically, anger-related dysregulation; however, further characterization of the emotion dysregulation processes associated with both childhood violence exposure and IPV victimization is critical to informing treatment and prevention efforts.

Examination of potential sex differences revealed that the associations observed in this study were consistent for men and women in this sample. These findings are inconsistent with those of a previous study that found anger to be more strongly associated with IPV victimization among men than women (Rutter et al., 2012); however, variations in study methodologies may account for inconsistent findings between studies, including differences in the measures of anger. Because both childhood family violence exposure and IPV are prevalent among women and men, potential sex differences and similarities should continue to be examined in future research.

The findings should be evaluated in light of several limitations. First and foremost, this study relied on cross-sectional data. As such, the temporal ordering of the observed relationships is unclear. It is possible that individuals who experienced IPV developed subsequent increases in anger-related dysregulation because of IPV as opposed to being a determinant of IPV victimization. Thus, our findings require replication in prospective studies. Second, the response rate for this study was modest, and participants in this study were primarily White university students, reducing the generalizability of the findings. Third, we used self-report measures of childhood family violence exposures, IPV victimization, and anger-related emotion dysregulation, raising concerns about shared method variance and retrospective recall bias. However, self-report measures of childhood family violence exposure have been found to be reliable, and when errors do occur, they are most often in the direction of underreporting previous trauma (Hardt \& Rutter, 2004). Fourth, the assessments of childhood physical abuse and interparental violence lacked detail about the timing and frequency of the events that occurred. Although young children are at highest risk for family violence (U.S. Department of Health and Human Services, Administration for Children and Families, Administration on Children, Youth and Families, Children's Bureau, 2012), it would have been ideal to have data regarding the age(s) at which violent episodes occurred to state definitively that family violence exposure occurred 
during childhood. Future investigations should use measures that are specifically designed to provide detailed assessments of these constructs, including contextual variables such as age of onset, duration, and frequency of the abuse. Fifth, childhood sexual and emotional abuse were not measured in this study. It will be critical to address both of these constructs in future research in this area. Finally, this study only evaluated IPV victimization; therefore, it is unknown whether participants in this study also engaged in IPV, including bidirectional violence. Evaluating anger-related dysregulation as a mechanism linking childhood family violence exposure to bidirectional aggression is a promising avenue for future research (Kuijpers, van der Knaap, \& Winkel, 2012).

If replicated, our findings hold promise with respect to informing clinical interventions with survivors of childhood family violence exposure. Although preliminary, these data suggest that individuals exposed to childhood family violence are important targets for preventive interventions focused on improving anger-related emotion regulation skills, such as skills to improve the modulation and expression of anger. Fortunately, researchers have already developed effective interventions to treat emotion regulation deficits based on emotion regulation theory and dialectical behavior therapy (DBT) for survivors of child abuse (Cloitre et al., 2006; Linehan, 1993). DBT has been applied to IPV survivors as a method for teaching emotion regulation skills, including anger modulation and expression, and the intervention appears to lead to decreases in emotional distress (Iverson, Shenk, \& Fruzzetti, 2009). The emotion regulation skills targeted in this treatment and other interventions that target anger-related emotion dysregulation may help reduce risk for IPV when applied to individuals who have experienced childhood family violence exposure and experience anger-related dysregulation.

\section{Acknowledgments}

This work was supported by the Department of Veterans Affairs, Veterans Health Administration, Health Services Research and Development (HSR\&D) Service as part of Dr. Iverson's HSR\&D Career Development Award (CDA 10-029) at the VA Boston Healthcare System.

\section{References}

Afifi TO, Murray EW, Cox BJ, Asmindson JG, Murray BS, Sareen J. Population attributable fractions of psychiatric disorders and suicide ideation and attempts associated with adverse childhood experiences. American Journal of Public Health. 2008; 98:946-952. [PubMed: 18381992]

Arbuckle, JL. AMOS 6.0 user's guide. Chicago, IL: SPSS; 2005.

Bandura, A. Aggression: A social learning analysis. Englewood Cliffs, NJ: Prentice Hall; 1973.

Bensley L, Van Eenwyk J, Wynkoop Simmons K. Childhood family violence history and women's risk for intimate partner violence and poor health. American Journal of Preventative Medicine. 2003; 25:38-44. http://dx.doi.org/10.1016/S0749-3797(03)00094-1.

Berzenski SR, Yates TM. A developmental process analysis of the contribution of childhood emotional abuse to relationship violence. Journal of Aggression, Maltreatment and Trauma. 2010; 19(2):180-203. http://dx.doi.org/10.1080/10926770903539474.

Black, MC.; Basile, KC.; Breiding, MJ.; Smith, SG.; Walters, ML.; Merrick, MT.; Stevens, MR. The National Intimate Partner and Sexual Violence Survey (NISVS): 2010 summary report. Atlanta, GA: National Center for Injury Prevention and Control, Centers for Disease Control and Prevention; 2011.

Campbell JC. Health consequences of intimate partner violence. Lancet. 2002; 359:1331-1336. http:// dx.doi.org/1310.1016/S0140-6736(1302)08336-08338. [PubMed: 11965295] 
Camras LA, Ribordy S, Hill J, Martino S, Spaccarelli S, Stefani R. Recognition and posing of emotional expressions by abused children and their mothers. Developmental Psychology. 1988; 24:776-781. http://dx.doi.org/10.1037/0012-1649.24.6.776.

Cattaneo LB, Goodman LA. Risk factors for reabuse in intimate partner violence: A cross-disciplinary critical review. Trauma Violence and Abuse. 2005; 6(2):141-175. http://dx.doi.org/ $10.1177 / 1524838005275088$.

Cicchetti D, Toth TL. Child maltreatment. Annual Review of Clinical Psychology. 2005; 1:409-438. http://dx.doi.org/10.1146/annurev.clinpsy.1.102803.144029.

Classen CC, Palesh OG, Aggarwal R. Sexual revictimization: A review of the empirical literature. Trauma, Violence, and Abuse. 2005; 6:103-129. http://dx.doi.org/10.1177/1524838005275087.

Cloitre, M.; Cohen, MR.; Koenen, KC. Treating survivors of childhood abuse: Psychotherapy for the interrupted life. New York, NY: Guilford Press; 2006.

Cloitre M, Scarvalone P, Difede J. Posttraumatic stress disorder, self- and interpersonal dysfunction among sexually retraumatized women. Journal of Traumatic Stress. 1997; 10:437-452. http:// dx.doi.org/10.1002/jts.2490100309. [PubMed: 9246651]

Coid J, Petruckevitch A, Feder G, Chung W, Richardson J, Moorey S. Relation between childhood sexual and physical abuse and risk of revictimization in women: A cross-sectional survey. Lancet. 2001; 258:450-454. http://dx.doi.org/10.1016/S0140-6736(01)05622-7. [PubMed: 11513908]

Costello AB, Osborne JW. Best practices in exploratory factor analysis: Four recommendations for getting the most from your analysis. Practical Assessment, Research \& Evaluation. 2005; 10(7) Retrieved from http://pareonline.net/getvn.asp?v=10\&n=7.

Cummings, EM.; Davies, PT. Children and marital conflict: The impact of family dispute and resolution. New York, NY: Guilford Press; 1994.

Desai A, Arias I, Thompson MP, Basile KC. Childhood victimization and subsequent adult revictimization assessed in a nationally representative sample of women and men. Violence and Victims. 2002; 17:639-653. http://dx.doi.org/10.1891/vivi.17.6.639.33725. [PubMed: 12680680]

Ehrensaft MK, Cohen P, Brown J, Smailes E, Chen H, Johnson JG. Intergenerational transmission of partner violence: A 20-year prospective study. Journal of Consulting and Clinical Psychology. 2003; 71:741-753. http://dx.doi.org/10.1037/0022-006X.71.4.741. [PubMed: 12924679]

Ford JD, Courtois CA, Steele K, van der Hart O, Nijenhuis ERS. Treatment of complex posttraumatic self-dysregulation. Journal of Traumatic Stress. 2005; 18:437-447. http://dx.doi.org/10.1002/jts. 20051. [PubMed: 16281241]

Gratz KL, Autumn P, Jakupcak M, Tull MT. Exploring the relationship between childhood maltreatment and intimate partner abuse: Gender differences in the mediating role of emotion dysregulation. Violence and Victims. 2009; 24:68-82. http://dx.doi.org/ 10.1891/0886-6708.24.1.68. [PubMed: 19297886]

Hardt J, Rutter M. Validity of adult retrospective reports of adverse childhood experiences: Review of the evidence. Journal of Child Psychology and Psychiatry. 2004; 45:260-273. http://dx.doi.org/ 10.1111/j.1469-7610.2004.00218.x. [PubMed: 14982240]

$\mathrm{Hu}$ L, Bentler PM. Cutoff criteria for fit indices in covariance structure analysis: Conventional criteria versus new alternatives. Structural Equation Modeling. 1999; 6:1-55. http://dx.doi.org/ 10.1080/10705519909540118.

Iverson KM, Dick A, McLaughlin KA, Smith BN, Bell ME, Gerber MR, Mitchell KS. Exposure to interpersonal violence and its associations with psychiatric morbidity in a U.S. national sample: A gender comparison. Psychology of Violence. 2012; 3:273-287. http://dx.doi.org/10.1037/ a0030956. [PubMed: 25232484]

Iverson KM, Jimenez S, Harrington KM, Resick P. The relative contribution of childhood family violence on later intimate partner violence among robbery victims. Violence and Victims. 2011; 26:73-87. http://dx.doi.org/10.1891/0886-6708.26.1.73. [PubMed: 21776830]

Iverson KM, Shenk C, Fruzzetti AE. Dialectical behavior therapy adapted for women victims of domestic abuse: A pilot study. Professional Psychology: Research and Practice. 2009; 40:242-248. http://dx.doi.org/10.1037/a0013476. 
Kuijpers KF, van der Knaap LM, Winkel FW. Risk of revictimization of intimate partner violence: The role of attachment, anger and violent behavior. Journal of Family Violence. 2012; 27:33-44. http://dx.doi.org/10.1007/s10896-011-9399-8. [PubMed: 22389553]

Koss MP, Oros CJ. Sexual Experiences Survey: A research instrument investigating sexual aggression and victimization. Journal of Consulting and Clinical Psychology. 1982; 50:455-457. http:// dx.doi.org/10.1037/0022-006X.50.3.455. [PubMed: 7096751]

Linehan, MM. Cognitive-behavioral treatment of borderline personality disorder. New York, NY: Guilford Press; 1993.

Lindhorst T, Beadnell B, Jackson LJ, Fieland K, Lee A. Mediating pathways explaining psychosocial functioning and revictimization as sequelae of parental violence against adolescent mothers. American Journal of Orthopsychiatry. 2009; 79:181-190. http://dx.doi.org/10.1037/a0015516. [PubMed: 19485635]

MacKinnon DP, Lockwood CM, Hoffman JM, West SG, Sheets V. A comparison of methods to test mediation and other intervening variable effects. Psychological Methods. 2002; 7:83-104. http:// dx.doi.org/10.1037/1082-989X.7.1.83. [PubMed: 11928892]

Marx BP, Heidt JM, Gold SD. Perceived uncontrollability and unpredictability, self-regulation, and sexual revictimization. Review of General Psychology. 2005; 9(1):67-90. http://dx.doi.org/ 10.1037/1089-2680.9.1.67.

McKinney CM, Caetano R, Ramisetty-Mikler S, Nelson S. Childhood family violence and perpetration and victimization of intimate partner violence: Findings from a national population-based study of couples. Annals of Epidemiology. 2009; 19:25-32. http://dx.doi.org/10.1016/j.annepidem. 2008.08.008. [PubMed: 18835525]

McLaughlin KA, Hatzenbuehler ML. Mechanisms linking stressful life events and mental health problems in a prospective, community-based sample of adolescents. Journal of Adolescent Health. 2009; 44:153-160. http://dx.doi.org/10.1007/s10802-012-9629-4. [PubMed: 19167664]

McLaughlin KA, Hatzenbuehler ML, Hilt LA. Emotion dysregulation as a mechanism linking peer victimization to internalizing symptoms in adolescents. Journal of Consulting and Clinical Psychology. 2009; 77:894-904. http://dx.doi.org/10.1037/a0015760. [PubMed: 19803569]

McLaughlin KA, Hatzenbuehler ML, Mennin DS, Nolen-Hoksema S. Emotion dysregulation and adolescent psychopathology: A prospective study. Behaviour Research and Therapy. 2011; 49:544-554. [PubMed: 21718967]

McLaughlin KA, Hatzenbuehler ML, Phil M. Mechanisms linking stressful events and mental health problems in a prospective, community-based sample of adolescents. Journal of Adolescent Health. 2009; 44:153-160. http://dx.doi.org/10.1016/j.jadohealth.2008.06.019. [PubMed: 19167664]

McNulty JK, Hellmuth JC. Neuroticism, marital violence, and the moderating role of stress and behavioral skills. Journal of Personality and Social Psychology. 2008; 95(1):166-180. http:// dx.doi.org/10.1037/0022-3514.95.1.166. [PubMed: 18605858]

Mennin DS, Holaway R, Fresco DM, Moore MT, Heimberg RG. Delineating components of emotion and its dysregulation in anxiety and mood psychopathology. Behavior Therapy. 2007; 38:284-302. http://dx.doi.org/10.1016/j.beth.2006.09.001. [PubMed: 17697853]

Messman-Moore TL, Long PJ. The role of childhood sexual abuse sequelae in the sexual revictimization of women: An empirical review and theoretical reformulation. Clinical Psychology Review. 2003; 23:537-571. http://dx.doi.org/10.1016/S0272-7358(02)00203-9. [PubMed: 12788109]

Milner JS, Thomsen CJ, Crouch JL, Rabenhorst MM, Martens PM, Dyslin CW, Merrill LL. Do trauma symptoms mediate the relationship between childhood physical abuse and adult child abuse risk? Child Abuse \& Neglect. 2010; 34:332-334. http://dx.doi.org/10.1016/jchiabu.2009.09.017. [PubMed: 20359748]

Moffitt TE, Caspi A, Krueger RF, Magdol L, Margolin G, Silva PA, Sydney R. Do partners agree about abuse in their relationship? A psychometric evaluation of interpartner agreement. Psychological Assessment. 1997; 8:47-56. http://dx.doi.org/10.1037/1040-3590.9.1.47.

Monson, CM.; Langhinrichsen-Rohling, J. The sexual assault measure. 1997. Unpublished manuscript 
Monson CM, Langhinrichsen-Rohling J. Sexual and nonsexual dating violence perpetration: Testing an integrated perpetrator typology. Violence and Victims. 2002; 17:403-428. http://dx.doi.org/ 10.1891/vivi.17.4.403.33684. [PubMed: 12353589]

O'Leary KD. Developmental and affective issues in assessing and treating partner aggression. Clinical Psychology: Science and Practice. 1999; 6:400-414. http://dx.doi.org/10.1093/clipsy/6.4.400.

Repetti RL, Taylor SE, Seeman TE. Risky families: Family social environments and the mental and physical health of offspring. Psychological Bulletin. 2002; 128:330-336. http://dx.doi.org/ 10.1037/0033-2909.128.2.330. [PubMed: 11931522]

Riggs, DS.; Caulfield, MB.; Fair, K. Risk of intimate partner violence: Factors associated with perpetration and victimization. In: Kleespies, P., editor. Behavioral emergencies: An evidencebased resource for evaluating and managing risk of suicide, violence, and victimization. Washington, DC: American Psychological Association; 2009.

Rutter LA, Weatherill RP, Taft CT, Orazem RJ. Examining gender differences in the relationship between dating violence victimization and anger in college students. Violence and Victims. 2012; 27(1):70-77. http://dx.doi.org/10.1891/0886-6708.27.1.70. [PubMed: 22455185]

Sappington AA, Pharr R, Tunstall A, Rickert E. Relationships among child abuse, date abuse, and psychological problems. Journal of Clinical Psychology. 1997; 53:319-329. http://dx.doi.org/ 10.1002/(SICI)1097-4679. [PubMed: 9169386]

Segrin C. Concordance on negative emotion in close relationships: Transmission of emotion or assortative mating? Journal of Social and Clinical Psychology. 2004; 23:836-856.

Shorey RC, Cornelius TL, Bell KM. A critical review of theoretical frameworks for dating violence: Comparing the dating and marital fields. Aggression and Violent Behavior. 2008; 13:185-194. http://dx.doi.org/10.1016/j.avb.2008.03.003.

Siegel JM. The multidimensional anger inventory. Journal of Personality and Social Psychology. 1986; 51:191-200. http://dx.doi.org/10.1037/0022-3514.51.1.191. [PubMed: 3735067]

Sobel, ME. Asymptotic confidence intervals for indirect effects in structural equation model. In: Leinhart, S., editor. Sociological methodology. San Francisco, CA: Jossey-Bass; 1982. p. 290-312.

Spitzer, RL.; Williams, JB.; Gibbon, M.; First, MB. Structured clinical interview for DSM-III-R Personality Disorders, screening questionnaire. Washington, DC: American Psychiatric Press; 1990.

Straus, MA. Manual for the conflict tactics scales. Durham, NH: Family Research Laboratory, University of New Hampshire; 1995.

Straus, MA.; Hamby, SL. Measuring physical and psychological maltreatment of children with the Conflict Tactics Scale. In: Kaufman Kantor, G.; Jasinski, JL., editors. Out of the darkness: Contemporary perspectives of family violence. Thousand Oaks, CA: Sage; 1997.

Straus MA, Hamby SL, McCoy SB, Sugarman DB. The revised Conflict Tactics Scales (CTS-2): Development and preliminary psychometric data. Journal of Family Issues. 1996; 17:283-316. http://dx.doi.org/10.1177/019251396017003001.

Street AE, Arias I. Psychological abuse and posttraumatic stress disorder in battered women: Examining the roles of shame and guilt. Violence and Victims. 2001; 16:65-78. [PubMed: 11281225]

U.S. Department of Health and Human Services, Administration for Children and Families, Administration on Children, Youth and Families, Children's Bureau. Child Maltreatment 2011. 2012. Retrieved from http://www.acf.hhs.gov/programs/cb/research-data-technology/statisticsresearch/child-maltreatment

Vega E, O'Leary KD. Test-retest reliability of the revised Conflict Tactics Scales (CTS2). Journal of Family Violence. 2007; 22:703-708. http://dx.doi.org/10.1007/s10896-007-9118-7.

Whitfield CL, Anda RF, Dube SR, Felitti VJ. Violent childhood experiences and the risk of intimate partner violence in adults: Assessment in a large health maintenance organization. Journal of Interpersonal Violence. 2003; 18:166-186. http://dx.doi.org/10.1177/0886260502238733. 


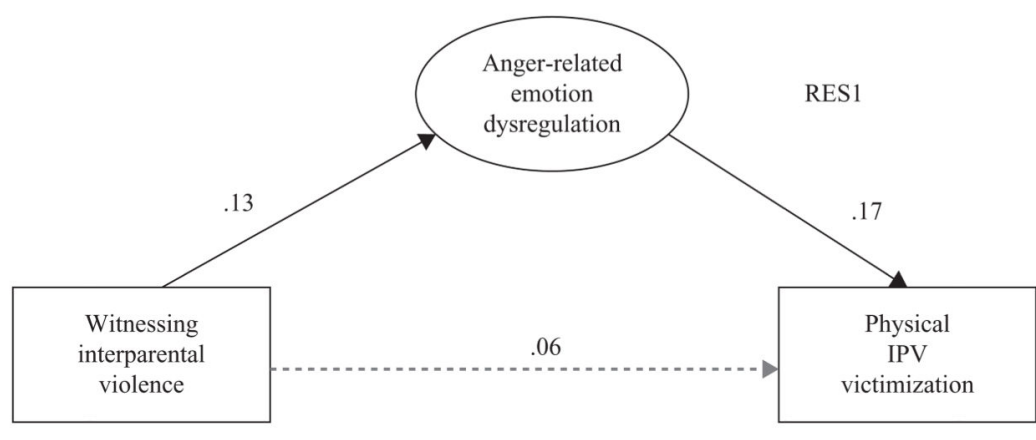

RES2

Figure 1.

Figure represents final mediational model for witnessing interparental violence and physical IPV victimization. Numbers represent standardized path coefficients $(\beta)$. All paths shown are significant $(p<.05)$, except those drawn with broken lines. The construct shown in a circle was modeled as a latent variable. Indicator variables are not displayed. 


\section{TABLE 1}

Female $(n=442)$ and Male $(n=228)$ Self-Reported History of IPV Victimization, Childhood Physical Abuse, and Witnessing Interparental Violence

\begin{tabular}{lccc}
\hline Type of Contact & Women $\boldsymbol{n}(\boldsymbol{\%})$ & Men $\boldsymbol{n}(\boldsymbol{\%})$ & Total $\boldsymbol{n}(\boldsymbol{\%})$ \\
\hline Physical IPV victimization & $165(37.3)$ & $99(43.4)$ & $264(39.4)$ \\
Sexual IPV victimization & $134(30.3)$ & $21(9.2)$ & $155(23.1)$ \\
Psychological IPV victimization & $304(68.8)$ & $147(64.5)$ & $451(67.3)$ \\
Childhood physical abuse & $145(33.1)$ & $89(39.0)$ & $234(35.1)$ \\
Interparental violence & $83(18.8)$ & $43(19.1)$ & $126(18.9)$ \\
\hline
\end{tabular}

Note. Some of the percentages reported in the table may not add up to $100 \%$ because of missing data. IPV = intimate partner violence. 


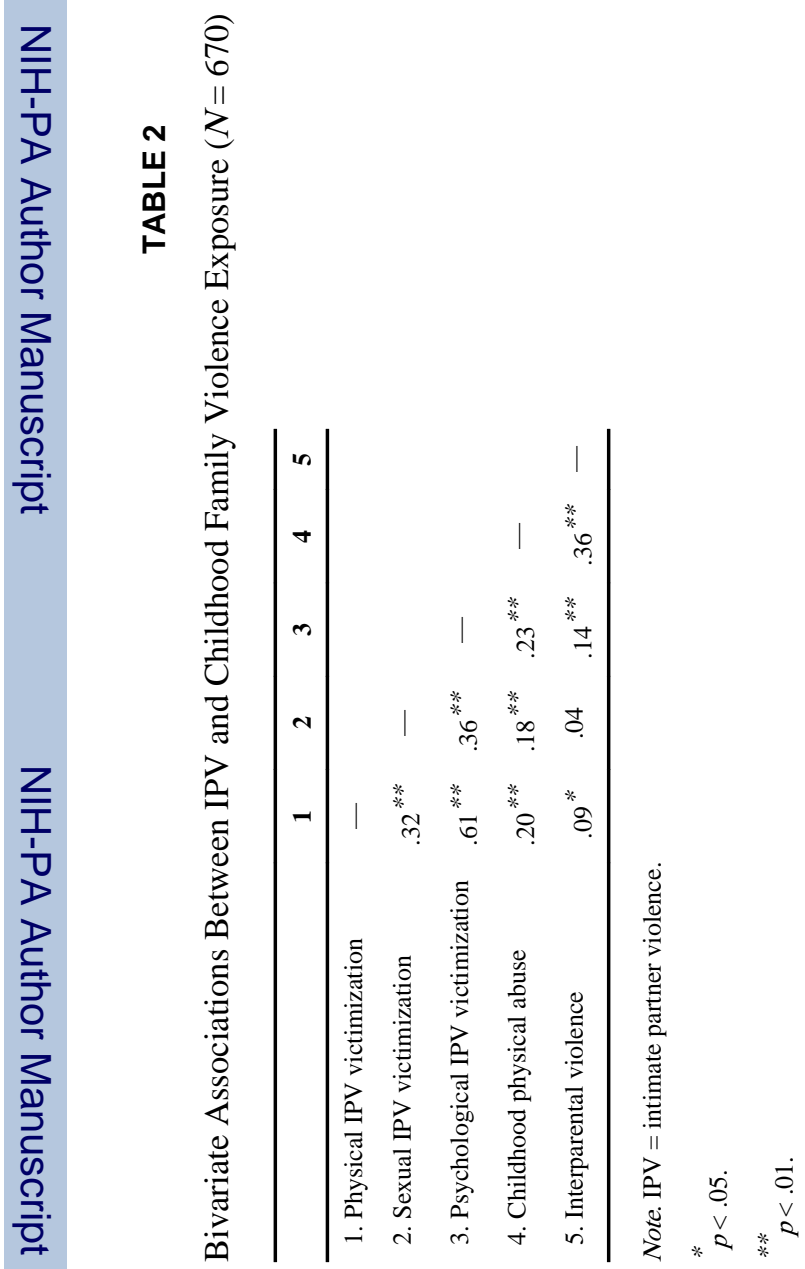

Violence Vict. Author manuscript; available in PMC 2014 November 04. 